\title{
Teaching how to learn with a wiki in Primary Education: what classroom interaction can tell us
}

\author{
M. Pifarré ${ }^{\mathrm{a}^{*}} \& \mathrm{Li} \mathrm{Li}^{\mathrm{b}}$
}

${ }^{a}$ Universitat de Lleida, Spain. pifarre@pip.udl.cat

bUniversity of Exeter, UK. li.li@exeter.ac.uk

*Correspondence author: M. Pifarré. Faculty of Eduction. Avinguda de l'Estudi General, 4. 25001 Lleida. E-mail: pifarre@pip.udl.cat. Tel: 973 706501973; FAX: 973706502

\begin{abstract}
Understanding how wikis are used to support collaborative learning is an important concern for researchers and teachers. Adopting a discourse analytic approach, this paper attempts to understand the teaching processes when a wiki is embedded in a science project in primary education to foster collaborative learning. Through studying interaction between the teacher and students, our findings identify ways in which the teacher prompts collaborative learning but also shed light on the difficulties for the teacher in supporting student collective collaboration. It is argued that technological wiki features supporting collaborative learning can only be realized if teacher talk and pedagogy are aligned with the characteristics of wiki collaborative work: the freedom of students to organize and participate by themselves, creating dialogic space and promoting student participation. We argue that a dialogic approach for examining interaction can be used to help to design a more effective pedagogic approach in the use of wikis in education, to shift into Web 2.0 learning paradigm and to equip learners with the competences they need to participate in knowledge co-construction.
\end{abstract}

Keywords: collaborative learning; dialogic teaching; Web 2.0 learning; Wiki; classroom interaction; elementary education. 


\section{Introduction}

Social technologies have become key features of leisure and work places, and also are starting to have a key role in education. Web 2.0 technologies have opened up new possibilities for open learning (Moskaliuk, Kimmerle \& Crest, 2009; Cole, 2009). In a short time we have shifted from a static web in which users had a passive role to a dynamic, collaborative and participatory web in which users have an active role, creating and sharing knowledge in a global web setting.

Different authors have agreed that Web 2.0 classes need to emphasise a learning culture based on participation, collaboration, creativity, dialog and knowledge creation (e.g. Wegerif, 2007; Lim, So \& Tan, 2010; Mercer, Warwick, Kershner \& Kleine Staarman, 2010). Particularly, cultural beliefs about learning with Web 2.0 technologies and practices focus on a dialectic relationship between personal and collaborative learning, highlighting socio-techno-spatial relationships which are advocated in current classrooms (Lim et al., 2010). Bonderup (2009) has further suggested that Web 1.0, characterised by knowledge transmission, the passive role of learners and a strong controlling role of the teacher has been dominant in current classrooms, while there is a need to advocate the Web 2.0 learning paradigm. Web 2.0, exemplified by wikis, is more focused on knowledge creation, student participation and less teacher control in learning. Students are considered more participants of the learning community while the teacher is more an expert participant who guides and helps students in developing a collaborative knowledge construction process. In this line of argument, it is important to know how schools can move forward to an eLearning 2.0 paradigm, and provide the educative community with valuable knowledge about: a) How web learning activities should be designed in order to promote collaborative knowledge creation models; or b) What competences students need to develop in order to be able to fully participate in collaborative knowledge creation activities; or c) What roles the teacher may play in order to promote eLearning 2.0 student competences.

Our paper follows this line of research, aiming to understand the characteristics of teaching processes when a wiki is used for collaborative learning in Primary Education. More specifically, in this paper we focus on the role of the teacher when a wiki environment is used in the classroom for promoting collaborative learning through the analysis of teacher-student interaction. Our study analyses how teacher dialogue 
may or may not contribute to enabling children to become progressively more able to solve a task collaboratively.

Wikis are characterized by a variety of unique and powerful information-sharing and collaboration features. Some researchers have drawn attention to the potential of wikis for collaborative learning because participants can create a shared digital artefact and this activity may facilitate the development of collaborative learning processes (Moskaliuk et al., 2009; Cress \& Kimmerle, 2008). However, while many researchers have described the broad range of potential pedagogical applications for wikis (Lund \& Smordal, 2006), few of them have studied how the teacher can support students' appropriation of collaborative construction of meaning through the articulation of each others' thoughts and ideas, and it is even rarer to study this issue in primary education. In this paper we attempt to examine the characteristics of teacher-student interaction when a wiki is used to enhance collaborative learning. We argue that such interaction is one of the key variables to help students create and engage in powerful, critical and reflective dialogues using Web 2.0 technologies that facilitate the co-construction of new knowledge.

Based on the above considerations, our study is grounded in the following three main concepts which are helpful to gain understanding about teacher-student interaction to promote web 2.0 competences and attitudes: a) socio-cultural theory to promote and analyse classroom interactions and participation in collective activities; b) the concept of "dialogic space” as a social space, a realm of activity within which people can think and act collectively (Wegerif, 2007) and c)“dialogic teaching” (Alexander, 2008) as a pedagogic approach in which teachers encourage students to participate actively, using group-based discussions to articulate, reflect upon and modify their own understanding.

Re-addressing the aim of our study along these lines, we examined how the teacher can create or hinder learning opportunities to enhance student interaction and collaboration using the wiki affordances for carrying out a collaborative task. To this end, we designed and implemented a science project in which twenty-five primary students and their teacher used a wiki environment for the first time, with the specific aim of establishing and supporting collaborative interaction, while engaging in a collaborative writing task.

\section{Sociocultural theory, sociogenesis and classroom interaction}


From the sociocultural theoretical perspective (Vygotsky, 1978), 'learning is conceptualized as knowledge construction through participation and negotiation, when language is used in context as a primary mediating tool. As Li (2011) puts it, 'language exchange is understood as a tool, which facilitates meaning negotiation, turn-taking in an activity, creation of a consensus between participants, and the developing of new forms of knowledge' (p.147). In schools, classroom interaction - as one form of social interaction - creates learning opportunities where knowledge is jointly constructed through participation, negotiation and collaboration. This learning opportunity, in turn, creates a foundation for individuals to develop.

This perspective is shared by Valsiner and van der Veer (2000) who proposed the concept of sociogenesis - 'the social genesis (i.e. development emergence) of the person' (p. 3) in studying the social mind and in particular intellectual interdependency. They discuss how different sociogenetic thinkers (such as P. Janet, J. M. Baldwin, G. H. Mead, and L. Vygotsky) have investigated the social nature of mind and pointed out the existence of two different epistemologies. One perspective is ontological which offers theoretical constructions that fuse the person and the social environment, and the concepts of participation and appropriation are key concepts to explain sociogenesis. The other perspective of sociogenesis emphasizes the idea that psychological phenomena emerge through social experience. They theorize that the person is viewed as distinct from the environment, yet interdependent with it, and they emphasize the notions of internalization and externalization.

As an alternative theoretical route Valsiner and van der Veer (2000) propose strengthening the understanding of the ways in which the person and social units relate and these authors tackle the concept of intellectual interdependency, that is, how the idea is socially constructed. This concept emphasizes the process of purposive communication efforts by persons and institutions, in which constructed ideas are transformed into new forms. Thus, this process can be seen an active construction of novel ideas in the interdependent relationship of the persons involved. Lund (2008) advocates that the concept of sociogenesis 'transcends the more individual aspects of learning and signals an epistemological shift from learning as a process within minds to learning as process between minds' and favours an expansion of the "social" and the dialectical concept of interaction within the zone of proximal development (ZPD) (p. 40). ZPD can be viewed as inhabited by individuals as well as a collective who can create a common ZPD through their interactions. Thus, this section aims to understand 
the social processes involved in the development of new ideas. In order to understand the social development of knowledge, we need to take consideration of the importance of the process of meaning negotiation, knowledge construction, participation, intersubjectivity and intellectual interdependency.

These processes are mediated through a symbolic tool, which Vygotsky further suggested as language. Language is seen as a tool to mediate and shape thinking. In the context of the classroom, the teacher uses language to perform different functions. One traditional view suggests 'teacher talk' falls largely into an IRF pattern (Initiation Response - Feedback) (Sinclair \& Coutlthard, 1975) and the first act of this pattern features 'closed questions' to which the teacher knows the answer (Wood, 1992). The purpose of this kind of talk is to help teachers identify what pupils are thinking, display knowledge or test children's factual knowledge of understanding, usually as a reiteration of information provided earlier by the teacher. To many researchers (Perrott, 1988; Van Lier, 1996), this kind of talk does not develop children's thinking or provide children with the possibility of participating. However, Mercer and Littleton (2007, p.36) suggest teachers' questions can also serve very useful functions in the development of children's learning, particularly to,

- encourage children to make explicit their thoughts, reasons and knowledge and share them with the class

- 'model' useful ways of using language that children can appropriate for use themselves, in peer group discussions and other settings (such as asking for relevant information possessed only by others, or asking 'why' questions to elicit reasons;)

- provide opportunities for children to make longer contributions in which they express their current state of understanding, articulate ideas and reveal problems they are encountering.

Research in the field of teacher-student interaction has claimed that teachers adopt different 'talk' strategies to support children in their understanding of the process of historical inquiry, for example, by using repeating, recasting and appropriation to develop technical language, by modifying questions to extend or reformulate students' reasoning, and by recycling ideas (Gibbons, 2003; Sharpe, 2008). In mathematics classes, Alexandar (2000) observed how Russian teachers encouraged students to share their misunderstandings with the class, and particularly how this helped to develop their and their peers' understanding. Studies in different contexts and subject areas suggest we cannot establish a simple way of describing or categorizing teacher talk if in-depth understanding of learning and teaching is desired. Rather, we need to understand learning through dialogue when language is used as the teacher's main pedagogic tool, as well as a cultural and mediating tool. 
In this line of reasoning, different studies have highlighted that with the right pedagogy the normally limited space for reflection between Initiation and Response in the IRF could be opened up into a dialogue in which children discuss alternatives and give reasons for positions. Wegerif (2007) has called this whole activity a 'IDRF' sequence with the D standing for the dialogic space opened up. 'IDRF' pattern would contribute to enlarging the social and dialectical conception of interaction within the ZPD.

\section{Dialogic Space}

In the context of Computer-Supported Collaborative Learning, Wegerif (2007,) claims that it is necessary to develop, through social interaction, a "dialogic space", which he sees as the social realm of the activity within which people can think and act collectively, thus opening up a space between people in which creative thought and reflection can occur (p.181). According to Wegerif, this approach offers a new perspective for our understanding of educationally-useful dialogue, not only including the aspect of critical thinking supported by the mechanisms of explicit reasoning and knowledge construction but also the less visible but possibly more fundamental processes of reflection and creative emergence.

We have highlighted the potential of using ICT to provide resources, opportunities and scaffolds for children to work and talk together, and for expanding, deepening and widening children's talk. This claim is even stronger in the context of Web 2.0 technologies because their main educational affordance is communication, interaction and collaborative participation in large communities and in a global perspective: everybody can communicate with everyone and everywhere. This affordance has opened a new era for learning. We agree with Wegerif (2007) that this new era can be exemplified as a "cacophony of voices offering countless opportunities for dialogic engagement with multiple perspectives on every topic” (p. 181). From this point of view, one main issue is to gain understanding in how to support our students to create and be engaged in powerful, critical and reflective dialogues using Web 2.0 technologies that let them co-construct new knowledge through online interaction with others.

Despite the potential of ICT for supporting a dialogic space that can lead to development of creative thinking and collaborative learning, researchers have highlighted that pedagogy should be aligned with the use of ICT to enhance creative 
thinking through productive dialogues. In Wegerif's words "the kind of teaching required would not only lead to the appropriation of particular voices in a debate but also the appropriation of the dialogical space of the debate” (Wegerif, 2010, p.1). From our perspective, this idea reinforces the teacher's role of providing children with opportunities not only to interact through ICT but also to “interthink” (Mercer, 2000), to advance in their joint and individual understandings of curriculum topics (Mercer \& Littleton, 2007), and to appropriate the dialogical space of the debate. To reach this educative objective, teaching has also to shift to a more dialogic style when using ICT.

\subsection{Dialogic teaching}

There are a growing number of studies that claim the necessity of developing the curriculum to support more active, dialogic approaches to primary learning and teaching (Mercer et al., 2010; Alexander, 2010). This claim is even more necessary when interactive technology is introduced in the classroom because it might potentially cause tensions between current government guidance on pedagogy in which the value of technology for whole-class teaching is emphasised and the need for developing teachers' diverse approaches for engaging children in active learning mediated by interactive technology (Kershner, Mercer, Warwick \& Kleine-Staarman, 2010).

In this line of argument, according to Alexander (2008), 'dialogic teaching harnesses the power of talk to engage children, stimulate and extend their thinking, and advance their learning and understanding’ (p.27). Mercer et al. (2010) give a detailed account of what the teacher actually does in a dialogic teaching approach:

(1) gives students opportunities and encouragement to question, state points of view and comment on ideas and issues which arise in lessons;

(2) engages in discussions with students, which explore and support the development of their understanding of content;

(3) takes students' contributions into account in developing the subject theme of the lesson and in devising activities which enable students to pursue their understanding themselves, through talk and other activity;

(4) uses talk to provide a cumulative, continuing, contextual frame to enable students' involvement with the new knowledge they are encountering;

(5) encourages the children to recognise that talk is not merely the prosaic chat of everyday life but is a valuable tool for the joint construction of knowledge. 
To sum up, sociocultural research treats 'communication, thinking and learning as processes shaped by culture, whereby knowledge is shared and understandings are jointly constructed' (Mercer \& Littleton, 2007, p.4) . This project takes this position in order to analyse the characteristics of teacher-student dialogue that may or may not contribute to opening a dialogic space which enhances students' collaborative learning processes to solve a complex task in a wiki environment.

\section{Affordances of Wikis and a dialogic space}

Wikis are part of the emergent generation of Web 2.0 tools and applications. There are different wiki engines, but each has, as a common feature, a collaborative web site that allows users to easily create, edit, revise, expand or link web pages to create a text collaboratively. Acting in this way, wiki participants become collaborative authors of a product of a collective creation. In blogs or forums, users can only leave responses or comments. In a wiki, however, users can modify existing entries and add new media information (text, images or web links). It is evident to wiki participants that they are dealing with an artefact that was created as the product of their collaboration -a collective product. According to Moskaliuk et al. (2009), this may encourage users to examine other people's opinions more closely and increase their knowledge more deeply as well.

Several researchers have drawn attention to the potential of wikis for collaborative processes in education (e.g., Parker \& Chao, 2007; Mak \& Coniam, 2008; Larusson \& Alterman, 2009). Parker and Chao (2007), for instance, emphasize that properties of a wiki can support collaborative and constructivist learning approaches. A meta-analysis of the literature about the use of wikis confirmed this idea, as wikis appeared to be used primarily for more open-ended activities such as collaborative writing projects (Grant, 2009), design-based learning (Rick \& Guzdial, 2006) or with inquiry learning and co-reflection (Yukawa, 2006).

The wiki possibilities that technically enable collaboration, knowledge sharing and personalisation provide educators with significant learning opportunities for creating socially engaging tasks that require active student participation and knowledge building (Mcloughlin \& Luca, 2002). In this line of argument, Woo, Chu, Ho \& Li (2011) in one of the few studies which used wikis with primary students, emphasised that the easy accessibility, simplicity and transparency of wiki pages helps learners to share information and resources among their team members and across groups, and 
makes it easier for students to work at their own pace. Furthermore, these authors highlighted in their study that students had positive perceptions about how wikis can improve collaborative group work and the quality of their work.

From the literature on knowledge construction (e.g. O’Loughlin, 1992) we have learned that constructivist learning requires that students engage in exploring possibilities, inventing alternative solutions, collaborating with other students, trying out ideas and hypotheses, revising their thinking, and finally presenting the best solution they can derive. Parker and Chao (2007) note that constructivist learning has been approached in wiki research, but most of these studies focus on activity design and none of them focus on the teacher's role. Although it is claimed that wikis could afford many learning opportunities to support socio-constructive collaborative learning processes, it is agreed that some form of pedagogy is required and a new teacher role needs to be considered. Furthermore, the relationship between sociogenesis and a collective view of ZPD might help for approaching learning in wikis. As we highlighted, Web 2.0 technologies can afford a collective activity and they have the affordances to potentially support a collective ZPD and a collective product of their collaborative learning processes. However, research has already pointed out that there is not a simple causality between technological collaborative features and use, and features of a collective activity mediated by technology must to be socially enacted (Lund, 2008).

In the promotion of the social development of ideas in a wiki, a teacher's model of learning and how s/he explicitly designs classroom work and promotes teacherstudent and student-student interaction to enhance learning opportunities that take advantage of the affordance of wikis to promote collective thinking is also a key element (Cole, 2009). Nevertheless, there is still little empirical research that shows how this objective can be realised in educational settings and how this role and teacher talk can help in reaching these learning objectives. Our study pursues this line of research and attempts to provide insights into this matter.

\section{The Research}

\subsection{Purpose and research questions}

The study reported in this paper is intended to explore how teacher-student interaction could create a dialogic space mediated by the affordances of wiki. We addressed this general objective through the design, implementation and evaluation of a 
classroom project using a wiki with students aged 9-10 years (grade 5). These data form part of a larger research project about the affordances of Web 2.0 technologies in education. Our main research question is:

How does the teacher dialogically support or fail to support students' collaborative learning in the wiki?

\subsection{Method}

Twenty-five primary students and their teacher participated in this study. The students came from an urban school in a lower socio economic area of Lleida (Spain). Students worked together in pairs with the computer. For face-to-face collaborative activities and to work asynchronously in the wiki, they were organised in groups of 6 . For the purposes of this paper, we analyzed one group of six students' talk in-depth. The transcript has been translated from Catalan. To protect participants, student and teacher names are given as pseudonymous. All appropriate consent was obtained from the school authorities, as well as from parents.

We designed a classroom-based project to prepare and give some support to students to work collaboratively in the wiki environment. The research project rests on principles of design-based research where interventions are iterative, theory-informed and aim to capture the ecology of the learning situation (Wang \& Hannafin, 2005). This educative project engaged students in three different learning phases with specific learning objectives (Figure 1) and the whole project lasted for 13 sessions of approximately one hour each. All class sessions were carried out by the same teacher. Although the teacher was not explicitly instructed to develop the educative project, she was knowledgeable about the "Thinking Together" program and worked closely with researchers in the design of the activities of the project. The teacher was not familiar with the use of wiki either as a user or as a teacher.

-Figure 1. Main characteristics of the collaborative wiki project

Phase 1: In this first learning phase, there were three face-to-face class sessions for which the main learning objective was to develop collaborative talk. In these sessions, a "thinking together" approach was used (Mercer, 2000) and students worked in groups of six on activities to enhance collaborative talk. 
Phase 2: In this second learning phase, students researched the topic they would write about later: the planet Mars and the scientific possibilities of setting up a colony there. At the end of this stage, every pair of students wrote an initial proposition giving some ideas related to the possibility of setting up a colony on Mars and what difficulties would need to be overcome and how. This phase lasted three class sessions.

Phase 3: Every three pairs of students joined in a wiki environment to write a final science text collaboratively. Seven class sessions were used for this stage. The first of these sessions focused on learning how to use the wiki spaces to write together. During the next six sessions, pairs took turns to work in the wiki for periods of about 10-15 minutes.

The wiki environment used in our work was built using a MediaWiki engine which was adapted because it can favour the negotiation and knowledge construction from the initial proposition of a text written by each pair to a text written collaboratively by a group. Furthermore, we think that the possibility to have a space in the wiki to produce content and another space to accompany this content of comments, discussion and annotations might support the use of the wiki in an interdependent and collective orientation. For this purpose, in our study the wiki design included two frames divided vertically. The left frame was "consultation space" and the right frame "writing space" (Figure 2). The consultation space contained two tabs: a) instructions to use the wiki and b) the students' initial ideas. These pop up as initial proposals from which students start the negotiation and composition processes in the wiki environment. The writing space also contained two tabs: a) negotiation page, where the pairs discussed and reached agreement on how they hoped to construct the joint text, and to decide on aspects of their collaborative writing such as: what sections the final text could have; what content each section would have; what content was needed in the group text; b) group page, the space where the group, formed by the three pairs, write the text collaboratively.

-------Figure 2. Design of the wiki environment: negotiation and group page

\subsection{Data collection}

The project contained 13 sessions altogether, including 6 wiki collaborative sessions. Each wiki collaborative session is approximately one hour and a total of 250 minutes' interaction data were recorded. We video-recorded the three pairs of one of the 
wiki groups while they were working in the wiki environment. Videos were transcribed verbatim and were analyzed using a sociocultural discourse analytic approach. Two researchers reviewed all the transcripts to select relevant extracts in relation to the research questions of the study. In this paper, three extracts belonging to the early stage of students starting to work at the wiki environment were chosen. This paper chose to present the first or second contribution of each pair at the beginning of the project because it is the stage when the teacher had to make an effort to help students to reach an understanding of how to work collaboratively in a wiki. More importantly, it is the stage when the teacher played a stronger role in shaping the nature of collaborative work, for example, by giving instructions and clarifying ideas.

The selected extracts are representative of the type of teacher-student interaction found in our study throughout the total 250-minute transcription. So, transcripts were analyzed qualitatively on the basis of the content and structure of the dialogical interactions between teacher and pairs of students. The analysis adopted a discourse analytical approach for three reasons. First of all, since learning is understood as a process of negotiation and knowledge co-construction, studying interaction can tell us the nature of such a process ( $\mathrm{Li}, 2011)$. Secondly, discourse analysis presents itself as a powerful tool to understand teaching and learning (Edward \& Westgate, 1994; Mercer, Littleton, \& Wegerif, 2004; Li, 2011). Finally, as Mercer (2004) points out, the merit of qualitative discourse analysis exists because 'the processes of the joint construction of knowledge can be examined in detail. The development of joint understanding, or the persistence of apparent misunderstandings or different points of view, can be pursued through the continuous data of recorded/transcribed talk.” (p. 141). Here in this study, we took a discourse analytical approach to present and comment on three selected extracts in terms of activity and the nature of teacher talk related to the way the teacher creates or obstructs students' learning opportunities within the wiki environment. The analysis of the data is organised around two axes about classroom talk through which the content and pedagogical purposes are realized: interactive/non-interactive and dialogic/authoritative (Mortimer \& Scott, 2003). Regarding the interactive/noninteractive dimension, we are concerned with different participants' contributions. Or in other words, who dominates the talk. In relation to dialogic / authoritative dimension, we focus on the weight of their contributions and whose idea is discussed, valued and heard. 


\section{Findings and discussion}

In the following analysis, we present data first and then provide comments for each extract.

\begin{tabular}{|c|c|c|}
\hline \\
\hline 1 & & \\
\hline $\begin{array}{l}1 \\
2\end{array}$ & Teacher: & Don't you have anything to say about Mariona and Adil's \\
\hline 3 & & This is not enough. If not, we will have to do too many \\
\hline 4 & & turns to the computer. Now, we should contribute our first \\
\hline 5 & & impressions about what we have read ((addressing \\
\hline 6 & & all the pupils)). \\
\hline 7 & & ((Nil deletes the signature and presses the enter key two \\
\hline 8 & & times)) \\
\hline 9 & Teacher: & No, you don't have to press it two times, consecutive... \\
\hline 10 & Nil: & Consecutive? \\
\hline 11 & Teacher: & Well, if you want to do it separately, here... come on... \\
\hline 12 & Teacher: & And here you can also write the parts which you think the \\
\hline 13 & & final text should have! Or if you think we should agree \\
\hline 14 & & with or disagree with... Or you can also ask things to your \\
\hline 15 & & classmates! Why do you say this or that or so, don’t \\
\hline 16 & & you think so? ((Someone calls teacher and she leaves)). \\
\hline 17 & & ((They write down: “About the text of”)) \\
\hline 18 & Moussa: & Do you write every full stop? \\
\hline 29 & Nil: & Ma...rio...na... ((he says while he is writing "Mariona-“, ol \\
\hline 20 & & while his partner is writing; it isn't clear who is writing \\
\hline 21 & & now)). ((They write: Adil”)) \\
\hline 22 & Nil: & The letter A, my God, what happens to the letter A of \\
\hline 23 & & Adil! \\
\hline 24 & & ((Nil and Moussa enter Mariona and Adil’s proposal)). \\
\hline 25 & Teacher: & You've got to bear in mind that the question... the \\
\hline 26 & & question from which you have to base your text... was.. \\
\hline 27 & & was... Could a human colony on Mars be designed? \\
\hline 28 & A pupil & another group: Yes! \\
\hline 29 & Teacher: & What problems would we have to overcome? How could \\
\hline 30 & & we do that? This question must lead your final text! \\
\hline
\end{tabular}

The first extract belongs to the first students' session in a wiki. It is the first time that these students had worked in the wiki environment. Like we have stated earlier, there were three text propositions in the "consultation space" while the "writing space" was empty. Before the extract we analyse here, the pair read the three text propositions and started to give their opinion in the "negotiation space”. While students were writing in the wiki, the teacher was observing them and began the interaction.

\footnotetext{
${ }^{1}$ Nil and Moussa are one pair of students. Mariona and Adil are another pair of students.
} 
Extract 1 can be classified as a non-interactive /authoritative talk, as the teacher dominates the floor and pupils have rather limited and brief turns (note Moussa only has one turn and her question is not answered in any way either). This might be because it is a new activity for students, and it is vital important for the teacher to make sure students understand the activity. We could describe the teacher's talk as teacher-direct dialogue (Karasavvidis, Pieters \& Plomp, 2003) as the teacher gives direct instructions about the task (lines 2 to 5), about wiki technology procedure (lines 9 and 11), about what students can negotiate and share in the wiki negotiation space (lines 12 to 16) and about strategies to accomplish the task (lines 25 to 27). Although this kind of talk may be appropriate at the early stage of collaborative work and to engage students in a new activity and using a new tool, from a socio-cultural perspective, it would also have been useful to help students to establish the culture for their collaborative work if the students were given an opportunity to 'self-pace' the parameters of their contribution in the wiki (in this case, how long their contribution in the wiki will be). Here, the teacher is framing and structuring pairs' contributions in the wiki, and clearly this is led by her pedagogical goal of what should be done in the wiki in order to solve the task and how students should construct their own understanding about what to contribute, how long and for what purpose.

In terms of discourse patterns, the teacher is using the language mainly to model and give direct instructions about task resolution in the wiki environment, and is using the language with two different purposes. On the one hand, she is providing three different examples of different kind of contributions in the wiki negotiation space (lines 12 to 16). These three different examples also have different objectives of a contribution in a wiki, namely: to propose an outline of the collaborative text, an opinion or ask a question to classmates requiring more information. On the other hand, the teacher is reelaborating the purpose of using a wiki and -to write a text collaboratively- and modelling a framework for student interaction (lines 25 to 27). It is clear that the teacher's pedagogical goal is to give instructions and model what content should be introduced in the wiki negotiation space. Implicitly, the teacher also has the objective of aiding students to understand how to negotiate in a wiki. However, the dialogue is noninteractive and authoritative in nature. Although giving instructions and direct modelling can be one first stage of engaging students in solving new activities (Hadwin, Wozney \& Pontin, 2005), the teacher's talk is restrictive and focused on task procedures 
rather than on the joint interpretation and definition of the new collective task (shared goal and actions).

From a socio-cultural perspective, how students construct knowledge in interaction within a specific setting and the resources that they appropriately use implies a focus on the total process of understanding and doing a task (Newman, Griffin \& Cole, 1984). In this line of argument, Lund and Rasmussen (2008), in a longitudinal study using wiki with students in higher education, argue that there is a need to align pedagogical as well as technological designs to support students in creating a representation of a more collectively-orientated task in order to enforce the collective aspects of knowledge construction. The process of understanding a task and following an instruction is not trivial, and when the task and the tool to solve it are new for the students, this understanding is even more difficult. The students of our study have to learn how to make individual contributions, interdependent with other students' ideas, which could be shared, understood and transformed into collective knowledge in the wiki environment. This cannot simply be done by following the teacher's instructions but students need support to reflect on the knowledge submitted in the wiki, how to interconnect the initial ideas of the different members of the group and how to create a collective representation of the task when using a collectively orientated tool.

From a dialogic perspective in which jointly negotiated meanings through dialogue is a key variable in computer-supported collaborative learning (Wegerif, 2007), we wonder if this non-interactive / authoritative talk can be any help for students to get a deeper understanding about how to contribute in a wiki in a constructive and creative way. Moreover, teacher-student interaction is not addressed to identify students' previous knowledge, doubts or thoughts about their wiki participation. An example of this statement could be that the teacher starts the interaction asking an open question that might begin the building of an open and wider dialogue (as D referred by Wegerif, 2007) about students' thoughts and feelings of how their contribution in the wiki could look like. Instead of creating an open dialogue (line 1), the teacher answers her own questions, blocking interaction with students and the possibility to use language to negotiate and create new meaning.

Extract $2^{2}$ :

1 Elias: $\quad$ teacher...can we start the text because we all agree on one

\footnotetext{
${ }^{2}$ Elías is a member of the second pair of students; he forms a pair with Begoña.
} 
thing and it's that we cannot go ((he speaks to teacher, who is behind the couple))

Teacher: but first you have to contribute something in the negotiation space

Elías: $\quad$ no... but...we'll put it after ...or shall we write it now?

Teacher: $\quad$ you write something here ((negotiation space)).

Elías: yes because later maybe we won't have time, will we?

Teacher: no but, write in the negotiation section what you think you agree and what you don't and you say: as we see we all agree, we could. Look, they two have said something, haven't they? About how text could be?.

Elías: they've already put the title.

Teacher: $\quad$ Yes.So let's see what you think about the title. To do your contributions it has to be done like this: you have to go to the end and click two intros.

Elías: $\quad$ where is this title?

Teacher: $\quad$ what? A human colony on Mars, possible or impossible? ((Teacher points at the screen,.))

This extract belongs to another pair of students and it is their first go in the wiki environment. Before the extract, this pair of students had read the text propositions - the contribution in the negotiation space and in the writing space made by Nil and Moussa who had written only the title of the collaborative text.

This extract is an example of interactive but authoritative talk. As the data suggests, this dialogue is initiated by a student, Elías, rather than the teacher, suggesting a more active learners' role. In the wiki environment, learners become more autonomous and independent to control content, pace and style of learning as students are provided with opportunities to elaborate their understanding, to reason their thoughts and to make sense of complex concepts. According to studies in maths, students could approach problems in multiple ways by posing solutions, asking for evidence and by explaining and clarifying their strategies (Kovalainen \& Kumpulainen, 2007). Particularly in this extract, Elias 'negotiated' with the teacher over what they wanted to do and reasoned why (line 1, 6, 8). In this negotiation, the teacher tried to use modelling and direct instruction to help completion of the task., for example, she modelled how to make contributions in terms of language and content (line 9), followed by an example of another pair (line 11). This modelling strategy can help children to stay on task.

Due to the nature of the talk being authoritative, the teacher is obstructing rather than providing 'dialogic space’ for children. For example, the teacher rejected Elias's proposal of 'starting the text' (line 4) as there was an implicit standard procedure in this 
collaborative project: making contributions by responding to peers' contributions in a negotiation page and then writing collaboratively on a wiki page. Here the teacher's tone is strengthened by using regulating words 'have to' (line 4). She wants children to follow her pedagogical plan -which is not socially grounded or agreed with students. So when Elias negotiates with her to write in a wiki page right away, she provides a direct instruction of 'you write something here' (line 7). Elias refuses to accept her instruction and negotiates with justifications this time (line 8). This suggests that in a collaborative working environment, Elias has shown a strong sense of being an independent learner, controlling the pace and style he engages with tasks. The teacher agrees with Elias (line 9) and changes her approach to convince Elias to follow her ideas (line 9 \& 10). By rejecting children's ideas, giving them direct instruction, controlling what and how to learn, the teacher has reduced the freedom children can have when learning in a wiki environment. When Elias insists on getting on with the title (line 17), the teacher seems to back down with her idea of 'making contribution first' by agreeing to let the children get on with what they are interested in: commenting on the title. This extract suggests that the teacher is obstructing learning opportunities by restricting what and how children could do a task, rather than providing support. Personal experiences and natural curiosity are viewed as appropriate elements in collaborative learning, while this extract suggests that the teacher is trying to adopt a more traditional teacher-dominant learning structure, where controlling, reducing freedom and giving direct instructions is obvious. One possible explanation is this might be due to the difficulties and tensions the teacher might face when adjusting from a traditional classroom to a learner-focused classroom (Nathan \& Knuth, 2003).

\section{Extract 3:}

\begin{tabular}{|c|c|}
\hline Teacher: & $\begin{array}{l}\text { ok, but this is a matter of content. But I'm referring to } \\
\text { things with which you can contribute. Or also about the } \\
\text { outline that the text should have to follow, do you have } \\
\text { any idea? Or maybe it's too soon? What do you think? Do } \\
\text { still have to discuss things? At the beginning you all agree } \\
\text { the fact that it's impossible to go there, don't you? At } \\
\text { least this is something. This is already a beginning. This } \\
\text { beginning would make sense, if you think this. But, apart } \\
\text { from this, what else could you say? You should have to } \\
\text { justify it, shouldn't you? ((She waits a few seconds)) We } \\
\text { have liked it, what else do vou want to sav, what vou like }\end{array}$ \\
\hline
\end{tabular}


and what else? Can you contribute with something new? Could you contribute with new things?

Adil $^{3}$ : $\quad$ yes, the rocket

Teacher: the rocket, with what other thing can you relate your rocket idea?

Adil: $\quad$ with the costume

Teacher: With the costume?

Adil: $\quad$ or that the costume was not heavy

Teacher: $\quad$ ok, but if you say that it's impossible to go there and you talk about it will be necessary a rocket, what happens? It's possible or impossible to go there? On what it depends?] Adil: $\quad$ on the time and if we do this...

Teacher: $\quad$ so you could write this. With what we agree and with what we don't agree. But it depends, if finally Elías and Begoña's invention becomes real, doesn't it? Maybe we could go there. Is this what you wanted to say, Mariona and Adil? So come on, let's see how you write this

This extract is students' second go working in the wiki environment. Previous actions that the pair had undertaken were focused on writing in the negotiation space about their agreement with the other pairs' contributions. The teacher viewed their work and began encouraging them to write more in the negotiation space.

This extract shows how the teacher uses a pedagogical tool to create or obstruct opportunities for learners to jointly complete the task through dialogues. At face value, this teacher does a lot of talk and there are a few extended teacher turns (line 1, 15, 18, 20, 24), which resembles a non-interactive and authoritative talk where the teacher 'controls the floor'. However, closer examination of the exchange suggests that the dialogue between the teacher and the student does not fall into the IRF tradition. On the contrary, the teacher kept initiating ideas by using strategies of repeating students' answers (line 15), increasing prospectiveness (line $15-2^{\text {nd }}$ part), seeking for clarification (line 18), recycling ideas (line 20) and making suggestions (line 24). These strategies enable the teacher to create cohesion in the text (Mercer, 2000) and to develop a discursive space for learners to elaborate or reformulate responses. This modified IRF sequence also allows the teacher to help learners to develop ideas (line $15-18,20-24$ ) and possibly build upon or challenge each others' (note the rocket was mentioned by another pair Elías and Begoña). Another distinctive feature of teacher talk as shown in this extract is the degree of possibility that learner contributions could have - as the key

\footnotetext{
${ }^{3}$ Adil and Mariona are the third pair of students..
} 
goal is to support the children to collaboratively complete the task by embracing and challenging each other's ideas. Here, the teacher demonstrates the skills of having students think about the task and keeping them on track by reiterating what they need to do (line 11-12) and modelling how they could communicate their ideas (line 24-28). This echoes a sense of 'scaffolding', when the teacher supports learners to master a task or achieve understanding through encouragement, focusing, demonstrations, reminders and suggestions (Mercer \& Littleton, 2007). In this extract, we can see evidence when the teacher enables learners' joint endeavours to promote the most effective opportunities for collaborative learning.

Equally, this teacher obstructs opportunities for collaborative learning through ‘reducing the degrees of freedom' (Mercer \& Littleton, 2007), closing down discussion and interfering with learners' contributions. The teacher suggests the focus should be placed on content and the outline which she believes to be important (line 1 to 3), from which we can see how she uses language to draw children's attention to what she would like them to do. Although this kind of intervention could to some extent keep children stay on task, and guide them through the activity, we would argue that in this particular task, the teacher's control and help might cause the opposite effect - restricting children's negotiation. It is difficult for children to develop arguments on complex constructs, a colony on Mars for instance, yet understanding can only develop through negotiating meanings. The alternative here for the teacher is to guide the discussion rather than giving instructions on what form they should take (e.g. developing an outline, which is beyond children's capability). This is reflected by Adil's response: a rocket. Teacher has her predefined pedagogical goal: children commenting on each other's contributions, developing an outline and justifying their argument. However, children were obviously not at the same page as the teacher and still at the stage of developing ideas, brainstorming and possibly negotiating their ideas. On the request of clarification from the teacher (line 16), Adil further elaborates his idea, which is an obvious opportunity the teacher to get children to participate in the discussion. However, the teacher closes down this opportunity, possibly due to the irrelevance to the task in her view or the restraint of the pre-defined pedagogical goal of completing the task. Another example of this is the teacher interfering with Adil's contribution (line 23). Although the teacher does not pose a question with a fixed answer, she accepts Adil's suggestion as a satisfactory answer and moves on. Again, in our view, her 
decision here is possibly determined by pre-defined pedagogical goal, which is to support children in completing the task.

Although these three extracts only provide a snapshot of interaction in a wiki environment, some general observations can be made if we situate these three extracts in the whole corpora to identify how typical they are. In one attempt to draw a general picture of the main features of teacher's interactions with her students, we categorize them broadly as authoritative / dialogic talk (Mortimer \& Scott, 2003). The authoritative talk where the teacher focuses on presenting, establishing and consolidating one specific point of view takes up $85.5 \%$ of the whole talk. On the other hand, the dialogic talk where the teacher and students consider, revisit, summarize and explore different views and possibilities consists of $14.5 \%$ of the whole talk. These extracts collectively suggest that the teacher tends to control the development of the interaction and project. There might be two reasons: First, like students, the teacher is working in a very different learning environment and teaching a quite difficult concept to the students. In order to help the students achieve the learning objectives, the teacher uses specific interactional strategies to control and maintain the natural flow of the lesson, namely modelling and giving direct instructions. However, when the teacher is able to create a dialogic space, as illustrated in Extract 3, she is able to use more interactive strategies, such as seeking for clarification, recycling ideas and making suggestions. It is argued that the teacher plays a vital role in directing the nature of the collaboration in such a task by using different interactional strategies. Closely related to the first reason is the teacher, without prior experience of using wikis in teaching, is probably finding it challenging. Particularly, the teacher needs to work within two epistemological positions to simultaneously support individual as well as collective production. In our extracts it can be seen the efforts of the teacher to help students to interdependent on each other idea's by seeking explicit links between individual ideas to those of others written in the wiki (e.g. extract 2, lines 9 to 12) or to relate individual ideas to those agreed by the group (e.g. extract 3 lines 20 to 22); or to contribute with novel ideas (e.g. extract 3, lines 1 and 2), in these examples we see an attempt of the teacher to help in the emergence of a collective ZPD.

At the level of affordances of wiki, we notice that the specific interactional strategies might be similar to the kind of talk teachers would use in traditional classrooms. However, even in these traditional exchanges, we can see the role of the wiki in affording students the chance to engage in collective activity. Wiki in these three 
extracts clearly offers a space for students to share ideas, negotiate opinions and construct collectively their writing. From our perspective, the wiki design used in our study, in which students have two frames, one with the initial pair text propositions and the other with the collective activity -negotiation and group page- provides an affordance to foster the intellectual interdependence among individual (pair) contributions and shape a collective activity. For example, in Extract 2, the teacher was guiding the students to comment and find links on the contributions from the first pair.

The wiki provides individual learners with opportunities to control their task. For example, in Extract 2, Elias showed a strong sense of being an independent learner who would like to make choices of how to approach the task. One might argue that this is not necessarily due to the wiki environment. However, we would argue that the non-lineal learning mode and possibilities of conducting the task via different methods that a wiki environment facilitates can enhance the autonomy the individual learners could develop in the process.

Obviously, another affordance that wiki has which is demonstrated clearly through the discourse is that learners bear different roles in the task. It is clear that in most of the extracts learners are working as writers and readers, and these roles switch spontaneously in the within-pair negotiation, teacher-learner interaction, and online negotiation between pairs.

Furthermore, the discourse evidence in this study also suggests that wiki is a complex platform that both teacher and students need longer and wider experience in order to better promote social construction of knowledge before students could fully use it in a collaborative task, as unfamiliarity with the environment also presents constraints (Extract 1).

\section{Conclusion}

Educational research has already reported the difficulties to move school pedagogy forward to elearning 2.0 (Bonderup, 2009; Lim et al., 2010). This paper has attempted to explore how teachers may create or obstruct dialogic space when a wiki is embedded in an instructional process through classroom interaction.

Different researchers have reported that wikis may help educationalists to create educative environments with significant opportunities for creating socially engaging tasks that require the creation of a sense of community (Grant, 2009) active student participation (Cole, 2009), deployment of creative thinking skills (Parker \& Chao, 
2007) and collaboration (Cress \& Kimmerle, 2008). Our study has suggested that the teacher used different strategies in her talk to realize these significant opportunities. For example, the teacher used the following support-creating learning strategies: repeating, recasting (re-elaborating), reformulating, increasing prospective, seeking for clarification, modeling, providing examples, recycling ideas / developing ideas, making suggestions.

However, we claim that the role of the teacher should be addressed to providing resources and opportunities to scaffold students in learning to think by means of the creation of a dialogic space in which different voices enable meaning to flow and new ideas to emerge. Developing productive educational dialogues do not lie only in constructing knowledge but in expanding awareness and promoting in students a capacity to question and to be able to think for themselves (Wegerif, 2010). In our casestudy, expected dialogic space was not created, although a preparation for collaborative working in a wiki was designed by means of embedding a "thinking together" approach in the educative project (Mercer, 2000). We have revealed difficulties in maintaining a web 2.0 collaborative paradigm and the classroom discourse features represent largely traditional classroom talk: IRF, explicit guidance and non-interactive / authoritative. We acknowledge non-interactive/authoritative talk has its place and value in web 2.0 supported learning environment, however, we strongly believe a full range of talk, particularly interactive / dialogic talk is desired in such a learning environment. The discourse pattern throughout this project suggests that the teacher talk is not taking into account students' thinking/ ideas, not sharing and negotiating the pedagogical model with students, controlling the direction of the task and dialogue, answering the teacher's own questions and reducing the freedom to explore other avenues. Literature has already reported that this type of teacher talk does not enhance students' learning autonomy and thinking skills that will enable a student to 'construct' his/her own learning. Neither these teaching strategies might be helpful in the development of those digital competences that will allow our students to actively participate in the creation of information dynamically in a global network society.

Research suggests that integrating Web 2.0 technologies necessitates the reconsideration of the culture of learning and teaching, for example the use of Web 2.0 technologies presents unique and complex challenges in terms of learning culture, structure and control relationships in classrooms. We claim that the characteristics of 
classroom talk presented in this paper suggest that wikis yield insufficient benefits of Web 2.0 tools when they are added (Moore, 2007).

Although wikis have many technological features to support collaborative learning, our study shows that these wiki affordances can only be realized through the design of a pedagogy that takes into account the role of task, teacher and student interaction (Engstrom \& Jewett, 2005). From our perspective, teacher talk and pedagogy should be aligned with the characteristics of wiki collaborative work: Freedom of students to organize and participate by themselves, features of talk of IDRF sequence in which teachers enhance students' discussion in order to find their own way to solve computer-based activities.

There are many issues a teacher needs to be aware of when guiding children to work in a wiki environment, such as the nature of collaborative tasks, the difficulty of the task, the pedagogical goal, the re-defined roles of children and the teacher. As pointed out by other researchers, wiki does not provide a default collaborative learning environment, the teacher needs to rethink his/her role and interaction with students in order to help them to understand the values of Web 2.0 technologies and construct new learning strategies (Grant, 2009; Crook, 2008, Parker \& Chao, 2007). The findings of our study can be seen in the same vein as that pointed out by Crook (2008) that the role of the teacher in a Web 2.0 environment is not simply about stepping back ,or controlling and directing learners' work. Learners have to learn how to participate and collaborate, and teachers need to play a role in facilitating and guiding this process, and in our study we showed interesting moments how this teacher role can be enacted.

Although our study is exploratory and case-based, in our opinion it contributes in pointing out the discrepancies in the views of learning, knowledge and the goals of the practice implicit in Web 2.0 and educational practices, and the challenges teachers have to face in raising awareness of the potentials and benefits of Web 2.0 technologies and in reflecting on their practices to ensure they create 'dialogic space' in such an environment. Teachers and learners need to develop shared strategies and understandings around a participatory and creative approach to technology use in schools (Clark, Logan, Luckin, Mee \& Oliver, 2009). Our project has a contribution to this understanding.

\section{Acknowledgements}


This research was funded by the Ministerio de Ciencia y tecnología of the Spanish Government (project number: EDU2009-11656). The authors would like to thank the teacher and the pupils for their participation in the study reported in this paper.

\section{References}

Alexander, R. (2000). Culture and Pedagogy; international comparisons in primary education. Oxford, Blackwell.

Alexander, R. (2008). Towards dialogic teaching: Rethinking classroom talk. 4th ed. York, England: Dialogos.

Alexander, R. (2010). Children, their world, their education: Final report and recommendations of the Cambridge Primary Review. Abingdon: Routledge

Bonderup, N. (2009). Web 2.0: Inherent tensions and evident challenges for education. Computer-Supported Collaborative Learning, 4, 343-363.

Clark, W; Logan, K.; Luckin, R.; Mee, A. \& M. Oliver (2009). BeyondWeb 2.0: mapping the technology landscapes of young learners. Journal of Computer Assisted Learning 25: 56-69

Cole, M. (2009). Using Wiki technology to support student engagement: Lessons from trenches. Computers \& Education, 52, 141-146.

Cress, U \& Kimmerle, J (2008). A systemic and cognitive view on collaborative knowledge building with wikis. International Journal of Computer-Supported Collaborative Learning, 3, 105-122.

CrooK, C. (2008). Web 2.0 technologies for learning: The current landscapeopportunities, challenges and tensions. Coventry: BECTA.

Edward, A.D. \& Westgate,D.P.G.(1994). Investigating classroom talk (2nd ed.).London/Washington,DC:Routledge, Falmer.

Engstrom, M. E., \& Jewett, D. (2005). Collaborative learning the Wiki way. TechTrends, 49(6), 12.

Karasavvidis, J., Pieters, J. \& Plomp, T. (2003). Exploring the mechanism through which computers contribute to learning. Journal of Computer Assisted Learning, 19, 115-128.

Kershner, R., Mercer, N.; Warwick \& Kleine Staarman. J. (2010). Can the interactive whiteboard support young children's collaborative communication and thinking in classroom science activities? International Journal of Computer-Supported Collaborative Learning, Volume 5, Number 4, 359-383

Kovalainen, M. \& Kumpulainen, K. (2007). The social construction of participation in an elementary classroom community. International Journal of Educational Research, 46(3-4), 141-158.

Gibbons, P. (2003). Mediating language learning: Teacher interactions with ESL students in a content-based classroom. TESOL Quarterly, 27 (2), 247-273.

Grant, L. (2009). “I DON'T CARE DO UR OWN PAGE!” A case study of using wikis for collaborative work in a UK secondary school. Learning, Media and Technology, 34 (2) 105-117.

Hadwin, A. F., Wozney, L. \& Pontin, O. (2005). Scaffolding the appropriation of selfregulatory activity: A socio-cultural analysis of changes in teacher-student discourse about a graduate research portfolio. Instructional Science, 33, 413450 . 
Larusson, J. A., \& Alterman, R. (2009). Wikis to support the "collaborative" part of collaborative learning. Computer-Supported Collaborative Learning, 4, 371402.

Li, L. (2011). Obstacles and opportunities for developing thinking through interaction in language classrooms. Thinking Skills and Creativity, 6 (3), 146-158.

Lim, W., So, H. \& Tan, S. (2010). eLearning 2.0 and new literacies: are social practices lagging behind? Interactive Learning Environments, 18 (3), 203-218.

Lund, A. \& Smordal, O. (2006). Is there a space for the teacher in a wiki? In Proceedings of the 2006 International Symposium on Wikis (WikiSys 06) (pp. 37-46). Odense, Denmark: ACM Press.

Lund, A. (2008). Wikis: a collective approach to language production. ReCALL European Association for Computer Assisted Language Learning 20 (1) 35-54.

Lund, A., \& Rasmussen, I. (2008). The right tool for the wrong task? Match and mismatch between first and second stimulus in double stimulation. International Journal of Computer-Supported Collaborative Learning, 3(4), 25-51.

Mak, B., \& Coniam, D. (2008). Using wikis to enhance and develop writing skills among secondary school students in Hong Kong. System, 36, 437-455.

McLoughlin, C. \& Luca, J. (2002). Experiential learning online: the role of asynccronous communication tools. In P. Baker \& S. Rebelsky (Eds.), Proceedings of the World Conference on Educational Multimedia.

Mercer, N. (2004). Sociocultural discourse analysis: Analysing classroom talk as a social mode of thinking. Journal of Applied Linguistics, 1(2), 13-168.

Mercer, N. (2000). Words and Minds: how we use language to think together. London: Routledge.

Mercer, N., Littleton, K., \& Wegerif, R. (2004). Methods for studying the processes of interaction and collaborative activity in computer-based educational activities. Technology, Pedagogy and Education, 13(2), 193-209.

Mercer, N.; Warwick, P.; Kershner, R. \& Kleine Staarman, J. (2010). Can the interactive whiteboard help to provide "dialogic space“ for children's collaborative activity? Language and Education, 24 (5), 367-384.

Mercer, N., \& Littleton, K. (2007). Dialogue and the Development of Children'sThinking: A Sociocultural Approach. London: Routledge.

Moore, M. G. (2007). Web 2.0: Does it really matter? The American Journal of Distance Education, 21(4), 177-183.

Mortimer, E. F. \& Scott, P. H. (2003). Meaning making in secondary science classrooms. Maidenhead, UK: Open University Press.

Moskaliuk, J., Kimmerle, J. \& Cress, U. (2009). Wiki-supported learning and knowledge building: effects of incongruity between knowledge and information. Journal of Computer Assisted Learning, 25, 549-561.

Nathan, M., \& Knuth, E. (2003). A study of whole classroom mathematical discourse and teacher change. Cognition and Instruction, 21, 175-207.

Newman, D., Griffin, P. \& Cole, M. (1984). Social constrains in laboratory and classroom tasks. In B. Rogoff \& J. Lave (Eds.) Everyday cognition. Development in Social context (pp. 172-193). Cambridge: Harvard University Press.

O’Loughlin, M. (1992). Rethinking science education: beyond piagetian constructivism toward a sociocultural model of teaching and learning. Journal of Research in Science and Teaching, 29 (8), 791-820.

Parker, K. R., \& Chao J. T. (2007). Wiki as a teaching tool. Interdisciplinary Journal of Knowledge and Learning Objects, 3, 57-72. 
Perrott, C. (1988). Classroom talk and pupil learning: guidelines for educators. In Action Research Tools, Part 3: Analysis of classroom discourse readings. Certificate of Teaching and Learning, NSW Department of School Education. Sydney: Harcourt Brace Jovanovich.

Rick, J. \& Guzdial, M. (2006). Situating CoWeb: a scholarship of application. Computer-Supported Collaborative Learning 1, 89-115.

Sharp, T. (2008). How can teacher talk support learning? Linguistics and Education, 19, 132-148

Sinclair, J., \& Coulthard, M. (1975). Towards an analysis of discourse: The English used by teachers and pupils. London: Oxford University Press.

Valsiner, J. \& R. van der Veer (2000). The social mind: construction of the idea. Cambridge: Cambridge University Press.

Van Lier, L. (1996). Interaction in the language curriculum: Awareness, autonomy \& authenticity. New York: Addison Wesley Longman Ltd.

Vygotsky, L. S. (1978). Mind in society: The development of higher psychological processes. Cambridge: Harvard University Press.

Wang, F. \& Hannafin, M. (2005). Design-Based research and Technology-Enhanced Learning Environments. Education, Technology, Research and Development (ETR\&D), 53 (4), 1042-1629.

Wegerif, R. (2007). Dialogic Education and Technology. New York: Springer.

Wegerif, R. (2010). Dialogue and teaching thinking with technology: opening, expanding and deeping the "inter-face". In K. Littleton \& C. Howe. Educational Dialogues. Understanding and promoting productive interaction. London: Routledge.

Woo, M., Chu, S., Ho, A., \& Li, X. (2011). Using a wiki to scaffold primary-School students'collaborative writing. Educational Technology \& Society, 14 (1), 43-54

Wood, D. (1992). Teaching talk: How modes of teacher talk affect pupil participation. In K. Norman (Ed.), Thinking voices: The work of the National Oracy Project. Sevenoaks: Kent: Hodder and Stoughton, 201-214.

Yukawa, J. (2006). Co-reflection in online learning: Collaborative critical thinking as a narrative. Computer-Supported Collaborative Learning, 1, 203-228. 
Figure 1. Main characteristics of the collaborative wiki project

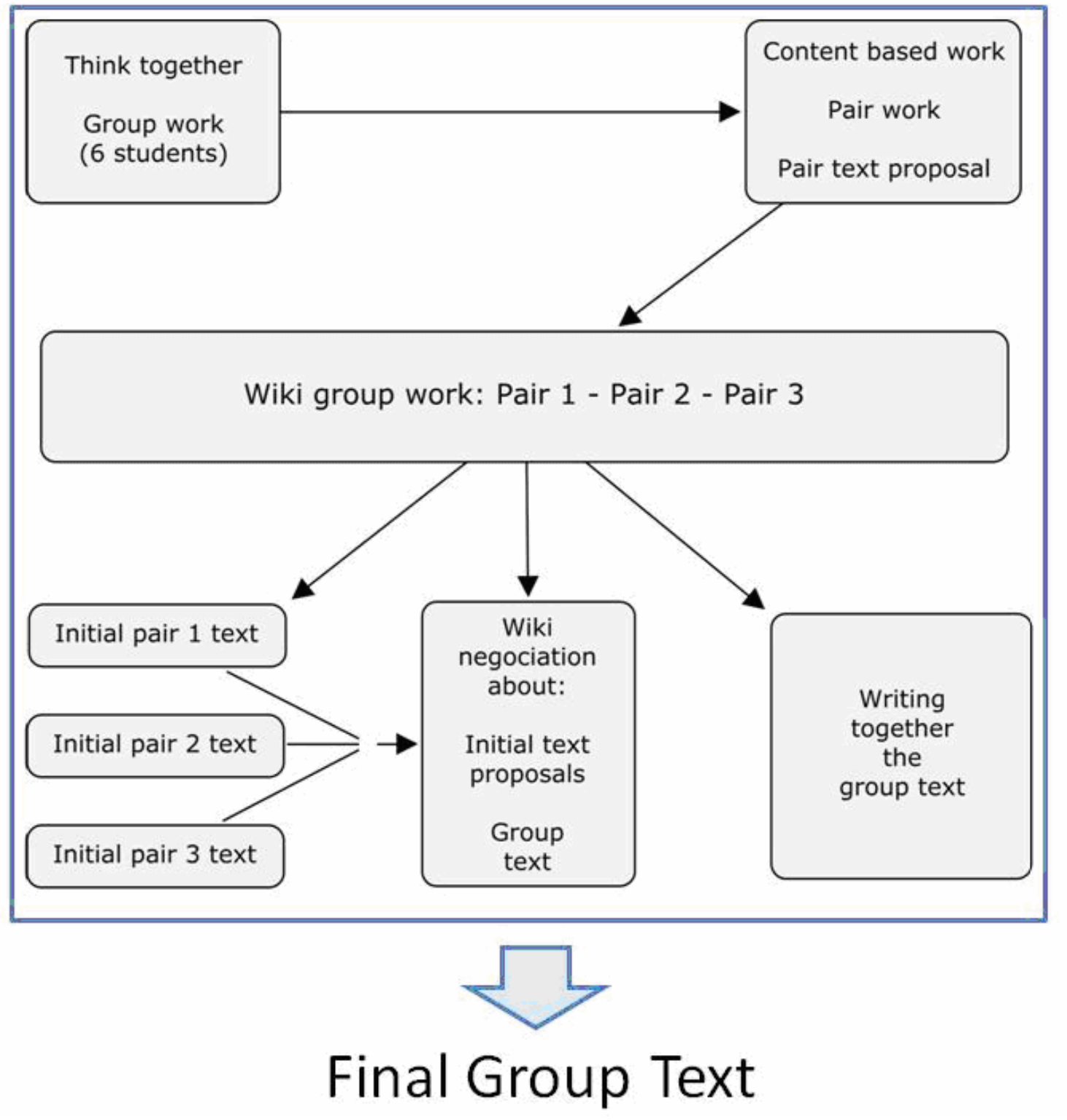




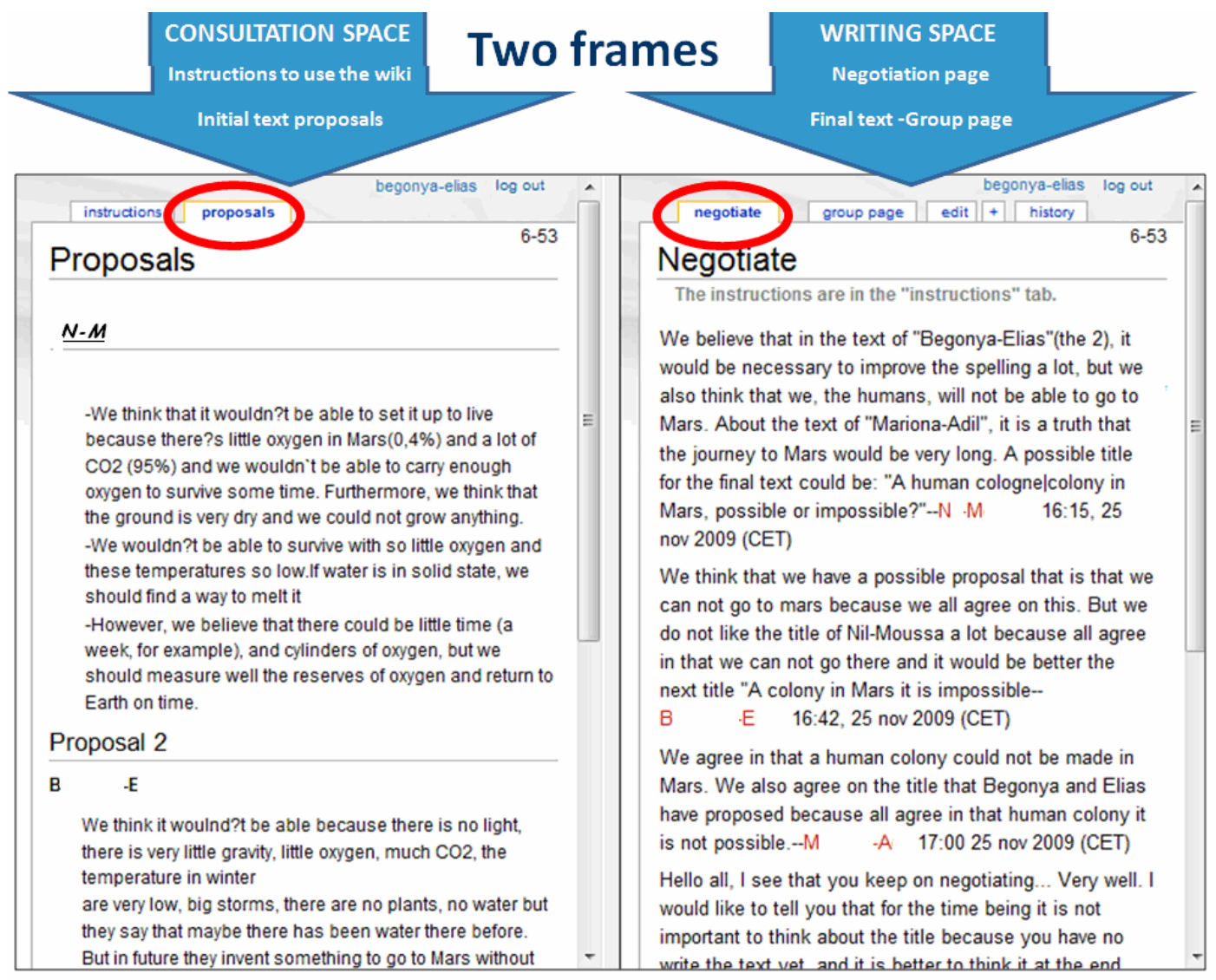

Figure 2: Design of the wiki environment (the screenshot has been translated to English). 